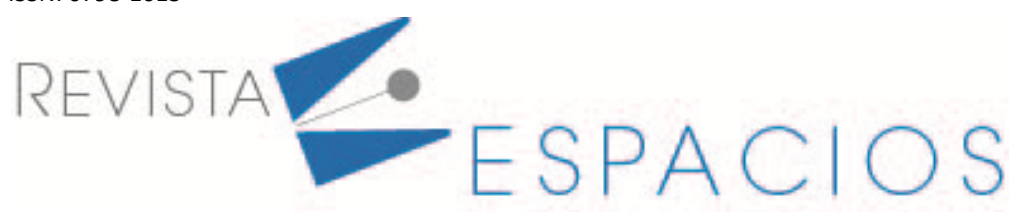

Vol. 41 (49) $2020 \cdot$ Art. 2

Recibido/Received: 13/07/2020 • Aprobado/Approved: 06/12/2020 • Publicado/Published: 23/12/2020

\title{
Study of the frequency of the sound waves emitted by the typical Colombian vallenato music instrument: The Guacharaca
}

\section{Estudio de la frecuencia de las ondas sonoras emitidas por el instrumento típico de la música vallenata Colombiana: La Guacharaca}

\author{
MEJIA REALES, José M. ${ }^{1}$ \\ MONROY-RAMÍREZ, Freddy A. ${ }^{2}$
}

\begin{abstract}
Resumen
Este artículo presenta un análisis de la frecuencia sonora emitida por el instrumento de la música Vallenata Colombiana, la Guacharaca. Se realiza una descripción de las ondas sonoras, relacionándolas con la estructura y material del instrumento. El análisis se llevó a cabo con estudiantes de undécimo grado del CASD Simon Bolivar en Valledupar, Colombia. La eficacia de la estrategia didáctica se analizó utilizando la ganancia normalizada Hake, observando una muy buena apropiación de los temas de parte de los estudiantes.

Palabras clave: guacharaca, música vallenata, frecuencia sonora, metodología de aprendizaje activo.
\end{abstract}

\begin{abstract}
This paper presents an analysis of the sound frequency emitted by the Colombian Vallenata music instrument, the Guacharaca. A description of the sound waves is made, relating them to the structure and material of the instrument. The analysis was carried out with eleventh grade students from CASD Simon Bolivar in Valledupar, Colombia. The effectiveness of the teaching strategy was analyzed using the Hake normalized gain, observing a very good appropriation of the themes by the students.

Key words: guacharaca, vallenato music, sound frequency, active learning metodology.
\end{abstract}

\section{Introduction}

As known, sound waves are longitudinal mechanical waves and the audible spectrum in mankind comprehend frequencies ranging between $20 \mathrm{~Hz}$ and $20000 \mathrm{~Hz}$. The study of the frequency of a sound and in general terms the frequency of an acoustic wave is very important due to the fact that it is associated, generally with the tone of the sound; nonetheless, the frequencies of the waves of sound are also determined by the way the sound is produced depending of the acoustic instrument is used, for example, when it is produced by scraping the trench along the guacharaca. Motivating school-age children and adolescents to study these topics in a traditional education framework is not an easy task, therefore when exploring with the aim of constructing the didactical strategies to study some waves of sound the guacharaca appears as a great motivational element for the

\footnotetext{
${ }^{1}$ Professor. Department of Basic Sciences. Universidad Popular del Cesar. Valledupar, Colombia. Email: josemejia@unicesar.edu.co.

${ }^{2}$ Retired Tenured Professor. Physics Department. National University of Colombia, Bogotá, Colombia. Email: famonroyr@unal.edu.co
} 
purpose, it also reinforces cultural aspects of vallenato as folklore music, and it is also important to highlight that this instrument is so important for the community that its acquisition or fabrication is not a problem. Being this instrument an idiophone (Majdalawi, 2005), instrument that produces its sound by scraping the trench along the scraped surface of the guacharaca, it permits to combine a number of variables involved in the production of the sound waves that can be analyzed.

This paper took as a starting point the possibility of identifying a mathematical relationship between the number of the wires, made up of cast iron, in the trench with which the guacharaca is scraped and the sound frequency emitted by the instrument as it varies in relation to the contact between the materials during the scrapping (Mejia Reales, 2016), (Mejia Reales \& Monroy-Ramirez, 2020). Since the body of the guacharaca has ridges on which the trench is rubbed, it is expected that the frequency of the sound will vary if the gaps among the ridges vary, this due to the fact that there is less or more friction interaction; consequently, the second exercise consisted on finding a possible relationship between this spacing of slots and the perceived sound frequency (Mejia Reales, 2016). The third exercise was based on the variation in the diameter of the guacharaca's body to determine whether or not it affected the observed sound frequency as the sound studied is the product of the external rubbing of the trench with the guacharaca and not the sound waves inside a tube (Mejia Reales, 2016). The last exercise carried out was intended to analyze the sound frequency perceived when changing the material of which the guacharaca is made, and thus analyzing some mechanical properties of the materials that are rubbed when playing the instrument, for example: that in comparison with to steel or iron, plastic (in this case polyvinyl chloride PVC) has less rigidity and greater elasticity. Likewise, it was considered that the thermal dilatation coefficient of plastic is 20 times higher than that of steel and iron; also taking into account the fact that the kinetic friction coefficient between the trench and the different materials varies (cast Iron - Wood 0,485; cast Iron - Steel 0,40; cast Iron - PVC 0.38) (www.engineersedge.com, 2010), (www.vaxasoftware.com, 2007), (Chaudhry, 2014). In the different exercises performed, the trench is rubbed against the guacharaca with a relatively constant frequency.

In order to achieve on the realization of the experiments required to study the sound frequencies emitted by the guacharaca, it was important to do it thought the implementation of a didactical sequence based on motivating and effective methodologies. For this reason, the Active Learning Methodology (ALM) was used in this work, since it changes the role of the teacher, as the owner of the knowledge, to that of a counselor, as a facilitator, where the result of the experiment acquires a fundamental role and consequently, the students are motivated to work individually and in groups, testing their preconceptions (Sokoloff \& Thornton, 1997). This analysis was carried out as part of the basic physics course with thirty eleventh grade students from the CASD Simón Bolívar Educational Institution in Valledupar, Department of Cesar in Colombia (Mejia Reales \& Monroy-Ramirez, 2020).

\subsection{The guacharaca}

There are various ways of classifying musical instruments, one of which was proposed by the musicologists Erich von Hornbostel and Curt Sachs, published in 1914 in their work Zeitschrift für Ethnologie, includes the acoustic principles that make different musical instruments sound (Maynor, 2010), (Doktorski, 1997). These principles classify the instruments in: Aerophones, which are instruments that use air as a source of sound and are subdivided into column aerophones and free aerophones (Maynor, 2010), (Doktorski, 1997). The chordophones, in which the sound is produced by means of the vibration of one or several strings in tension and are usually subdivided in four categories according to the mode of excitation: pointed with the fingers or with the help of a plectrum (harps, guitars, bandurria, lutes, vihuelas, psalteries, harpsichords), rubbed with a bow (violins, etc.), or hit with mallets (pianos, eardrums) (Maynor, 2010), (Doktorski, 1997). Membranophones are those that produce sound by means of one or more membranes lying on the openings of truck tubes (drums), (Maynor, 2010), (Doktorski, 1997). Electrophones are instruments that produce different sounds by generating and varying 
electrical currents. They are usually subdivided into mechanical-electric instruments (mixing mechanical and electrical elements) and radio-electric ones (entirely from electrical oscillations), (Maynor, 2010), (Doktorski, 1997). The fifth group of musical instruments are the Idiophones, which are constructed of materials that are naturally sonorous and can produce their sounds in various ways: they are percussed, dotted, shaken, rubbed or scraped; the guacharaca belongs to the last group and is one of the fundamental musical instruments of Colombian vallenato music (Gutierrez Hinojosa, 1992).

Vallenato is a genre of folklore music that is frequently performed, heard and danced by students of the CASD Simón Bolívar E.I. It is original of the Caribbean coast, with the greatest popularity in the province of Padilla, and located in north of the department of Cesar, south of the Guajira and east of the Magdalena in Colombia. It is currently recognized nationally and internationally for its musical airs: paseo, merengue, puya, son and tambura (Quiroz Otero, 1983), and also due to the brilliant combination of three cultures: the European accordion, the indigenous guacharaca and the African box. Thanks to all these expressions, vallenato was declared an intangible cultural heritage of humanity by UNESCO in 2015 (Marca Pais Colombia, 2015).

The guacharaca is a musical instrument with indigenous origins, it was adopted by the vallenato genre by the half of the XX century. Its name is derived from a bird -guacharaco- whose chant is imitated by its execution. This 'humble' instrument, so called because of its low cost and versatility, it belongs to the family of the stems, pieces of cane or calabazos, and it is part of the musical family of the idiophones, because the sound is produced by the vibration of a body (comb or trench) after being scraped against the guacharaca.

Figure 1

Guacharaca, a typical instrument in vallenato music.
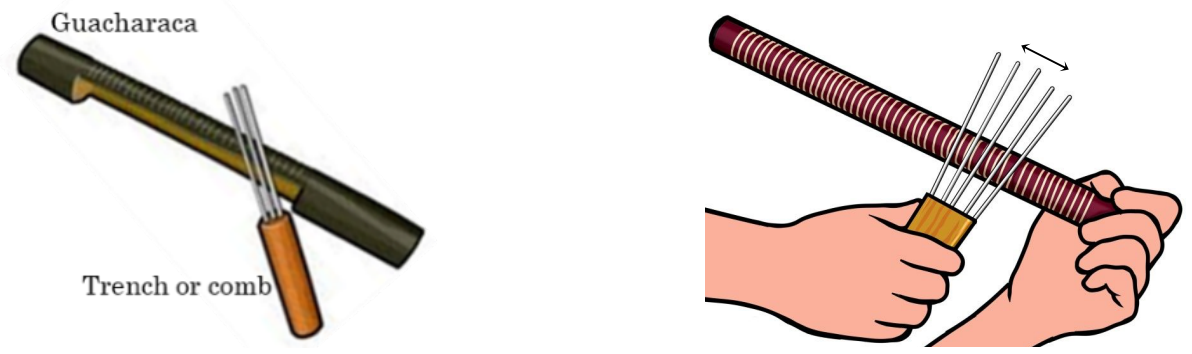

Source: (Mejia Reales, 2016)

This concave friction musical instrument is composed of two elements: the guacharaca which is made from the stem of "La uva de Lata" or Corozo palm (Bactris guineensis), which is hollow in the lower central third, and has longitudinal and transversal carved ridges on its surface (its interior is shaped like a canoe). It typically has a diameter of $4 \mathrm{~cm}$ and a length of $40 \mathrm{~cm}$, the trench or comb consists of pieces of wire (cast iron) of different lengths that are inserted into a wooden handle. Its total length is usually 26 centimeters, distributed as follows: 15 centimeters for the handle and 11 centimeters for the wires (Gutierrez Hinojosa, 1992).

This musical instrument that tries to render the chirping of the guacharaco (Orfalis rificauda), is nowadays a fundamental part of the typical instruments of Colombian vallenato music. To play it, one hand holds the part made from the stem of corozo wine palm, and with the trench, it is gently scraped with the other hand, positioned generating right angles with the ridges. This instrument can produce a powerful rhythm, and by varying the speed of the scraping, very high frequencies can be obtained if scrapped energetically as opposed to the low frequencies obtained when the scraping is slow, such as in the case of the "charrasca", the venezolan musical instrument. 
Depending on the material with it is constructed and the shape of its slots, the following types of guacharaca can be distinguished: the canned grape stem guacharaca with the ridges in a horizontal manner, the canned grape stem truncated guacharaca with the slots in a horizontal manner with other oblique ridges over these, and those constructed in metal with a series of horizontal and vertical holes (güiro) of different diameters and lengths (Gutierrez Hinojosa, 1992). In this work, only guacharacas with horizontal ridges were studied (Mejia Reales, 2016).

\section{Didactic strategy based on the Active Learning Methodology}

The Active Learning Methodology (ALM) is one of the didactic strategies comprehended within constructivism as a learning theory and suitable when it is intended the experiment to be the protagonist in the teaching-learning process since it allows the construction of knowledge through the direct observation of the real world. Its structure can be summarized in the following steps, called PAODS (Sokoloff \& Thornton, 1997):

Prediction: in this stage students set up a proposal on what may happen when facing a certain situation of phenomena.

Activity: A schema of work is developed with clear objectives following proposed activities.

Observation: Observation and measurement of the phenomena permit student to get familiar with the variables involved in the case of study.

Discussion: The results are interpreted and compared with the predictions and thus with those results corresponding with the theory.

Synthesis: The concepts or relationships studied among variables are interrelated and there is an analysis of the initial proposals and the nonconformance are given an explanation based on the theory and elements studied (in the best case carried out by the students).

In the $A L M$, each student is the central axis in the development of its abilities to develop critical thinking, foster independent thinking, individual and group work, direct experimental discovery, and debate (Sokoloff \& Thornton, 1997).

Throughout the teaching process there were two groups of students; a control group with which the contents are developed implementing traditional methodology, in which the teacher is the one who teaches the course through classic classes and the experimental group, with which the didactic proposal was developed using the $A L M$. In order to establish a comparison of the effectiveness of the proposal between the two groups, it includes a diagnostic assessment and a final evaluation (similar to the initial one, but not identical). These instruments together make it possible to compare the results of the proposal and the progress of the students' knowledge.

\section{Procedure}

To measure the frequency of the sound emitted by the guacharaca, the free software called Visual Analyser 2014 rel 0.3.1 STD 64 bit was used, which has similar functions to a typical oscilloscope. The figure 2 shows a screenshot indicating the main parts used. 
Figure 2

Screenshot of the Visual Analyser software used as a digital oscilloscope to measure the sound frequency emitted by the guacharaca

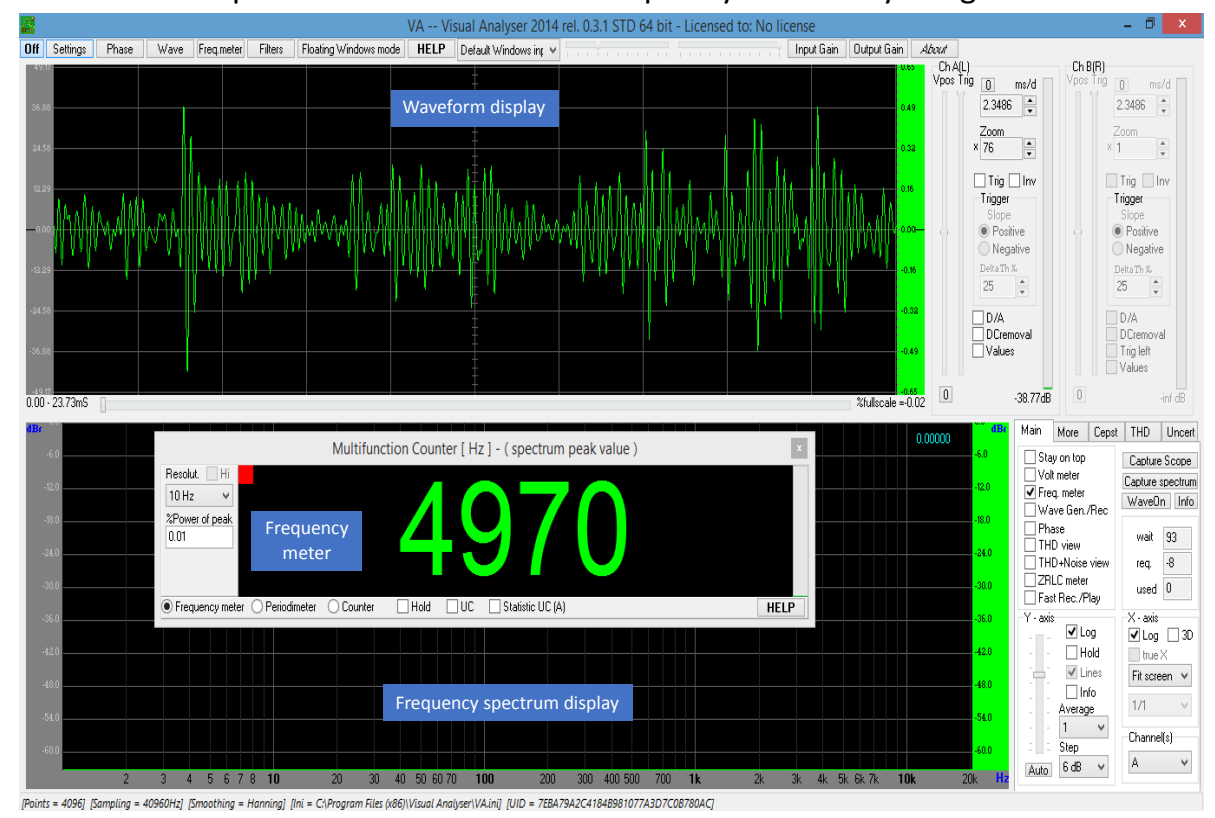

Source: (Mejia Reales, 2016)

The visual analyser software in the upper part shows the waveform and the respective commands for its visualization, in the lower part it shows the frequency spectrum of the sound detected with the computer's sound card, being able to easily identify the highest frequency peak (usually on a logarithmic scale), which corresponds to the fundamental frequency of the detected sound; it is also possible to show numerically the average sound frequency detected in a predetermined time interval, by means of a frequency meter. Depending on the range of frequencies to be measured, a resolution can be stipulated in the latter, which for the case was $10 \mathrm{~Hz}$, which will be directly related to the uncertainty in the measurements.

This free software was installed on a $12 \mathrm{~Gb}$ RAM, 1 TB HD, $2900 \mathrm{MHz}$ speed, 64 bit laptop, which was connected to a 50 in. television for viewing purposes.

Since there was a doubt as to whether or not the results of the sound frequency measurements could be affected by the performer of the musical instrument, a previous exercise was done in which several performers ( 3 male students and 3 female students) to carry out several tests (minimum 20), trying to keep the frequency of rubbing the carving on the guacharaca constant, and thus measure the sound frequency emitted by the instrument in each case. With this, the sound frequency averages obtained by each performer and by the total number of performers were calculated. With this exercise, two conclusions were obtained: the average sound frequency measured by female students was slightly lower than the average frequency measured by men (the difference was less than $2 \%)$. On the other hand, it was observed that the averages of all the performers varied by less than $10 \%$ of the general average of frequencies measured by the 6 performers, which allowed us to infer that, although the measured sound frequency changes from performer to performer, their differences are so small that, for this exercise, can be assumed within the uncertainty of the measurements. 


\subsection{Relationship between the frequency of the sound wave emitted by the guacharaca and the number of wires in the trench}

With the purpose of finding the average sound frequency emitted by the guacharaca in terms of the number of threads of the trench, keeping the material constant ("caña de flecha" or Gynerium sagittatum), and $1 \mathrm{~cm}$ of separation between the ridges in the guacharaca and using trenchs of $1,2,3,4,5$ and 6 threads, an experimental guide of active learning was designed where twenty sounds were produced with a constant frequency of friction.

Figure 3

(a) Production and visualization of the frequency of the sound emitted by the guacharaca. (b)Trenches with different number of wires.

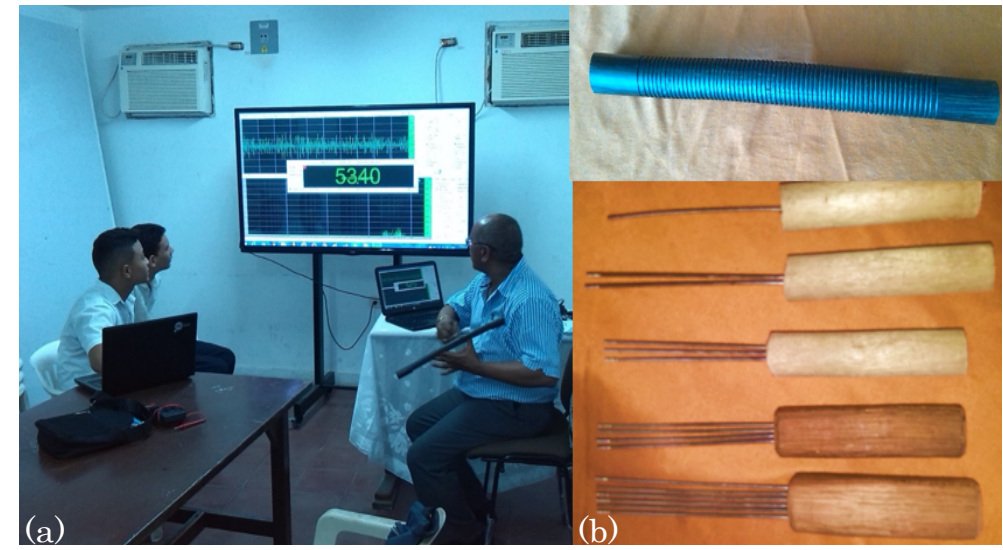

Source: (Mejia Reales, 2016)

The results of the average sound frequencies for each number of threads in the trench were plotted and with their trend line and extrapolation the equation was found that related the variables.

From Figure 4 it can be deduced that between the average sound frequency and the number of wires in the trench there is an approximately linearly increasing slope ratio of $529,11 \pm 53 \mathrm{~Hz} /$ wire.

Figure 4

Average Frequency: vs: number

of threads in the Guacharaca.

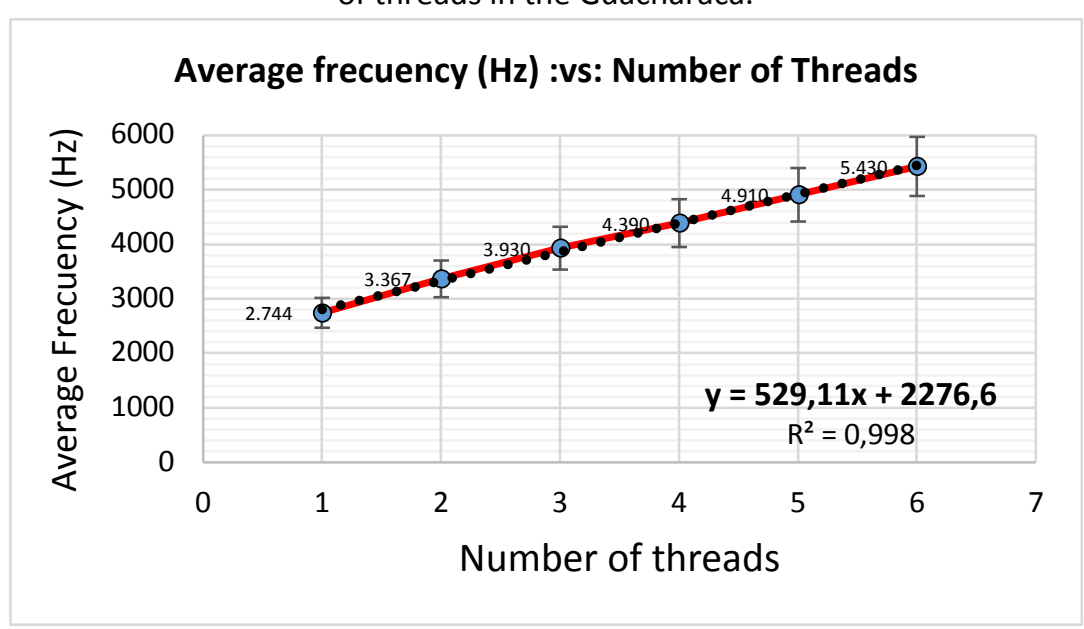

Source: (Mejia Reales, 2016) 


\subsection{Relationship between the frequency of the sound wave emitted by the guacharaca and the separation between ridges on its surface}

Using guacharacas constructed in plastic (polyvinyl chloride PVC) and equal diameter (3/4 in) with separation slots of $5 \mathrm{~mm}, 10 \mathrm{~mm}, 15 \mathrm{~mm}$ and $20 \mathrm{~mm}$ and a five thread trench, twenty sounds were produced with a constant friction phase, with the purpose of finding the average sound frequency emitted by the guacharaca as a function of the separation between slots with which it was constructed.

Figure 5

(a) Guacharacas constructed with identical material but different spacing between carven ridges (b) Sound production of the guacharaca and its visualization.
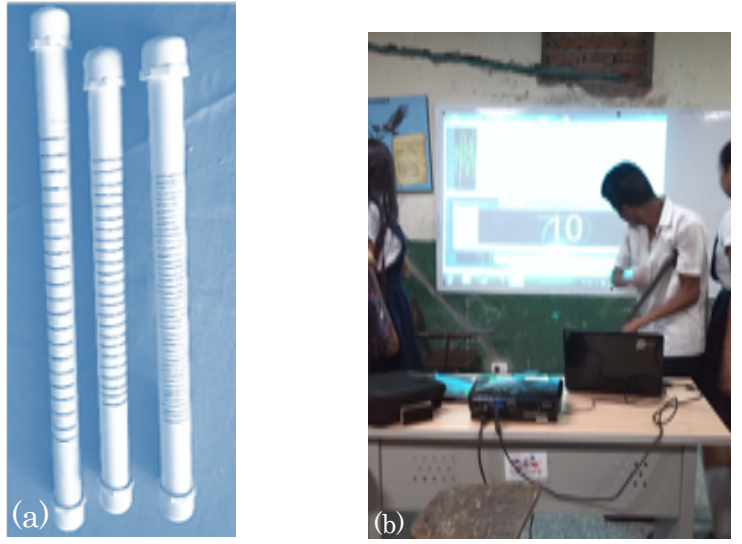

Source: (Mejia Reales, 2016)

Figure 6

Average Frequency: vs: Slot spacing on the guacharaca

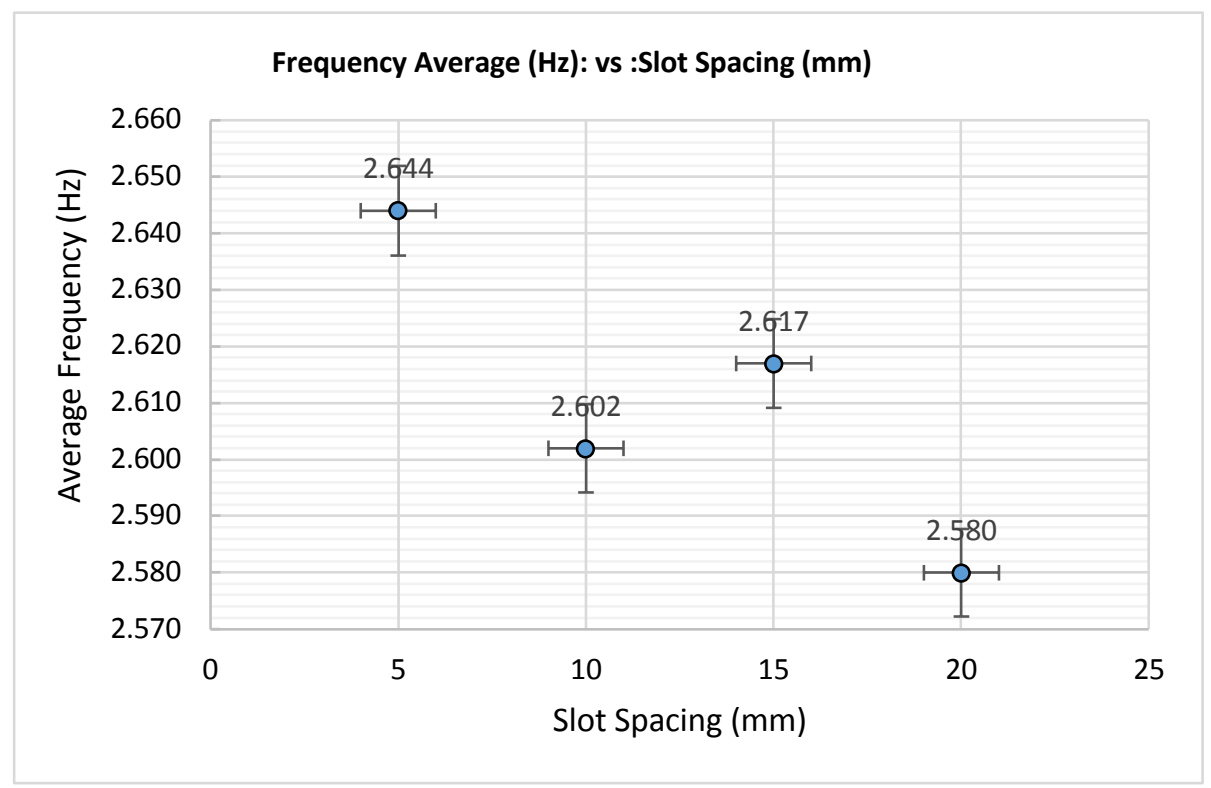

Source: (Mejia Reales, 2016)

Thanks to the practice carried out with the students, it was found that as the separation between the slots increases, the sound frequency emitted by the guacharaca is lower and the sound becomes deeper, but it was not possible to define a specific and unique relationship between the variables subject of study, although the 
experiment was repeated at least 20 times, probably because the performer did not achieve a very constant scraping frequency.

\subsection{Relationship between the frequency of the sound wave emitted by the guacharaca and its diameter, keeping the separation between the grooves constant and the same kind of material}

Guacharacas were manufactured in polyvinyl chloride PVC with diameters of $1 / 2$ in, $3 / 4$ in, 1 in and 2 in. Using a five-wire trench, sounds were produced by rubbing it over the scraped surface of the guacharaca with almost constant frequency. The experiment was repeated at least 20 times and the average sound frequency was calculated to see if there were any variation when changing the diameter of the guacharacas.

Figure 7

(a) Guacharacas constructed with PVC and different diameters

(b) Production and visualization of the frequency of the sound emitted by the guacharaca.

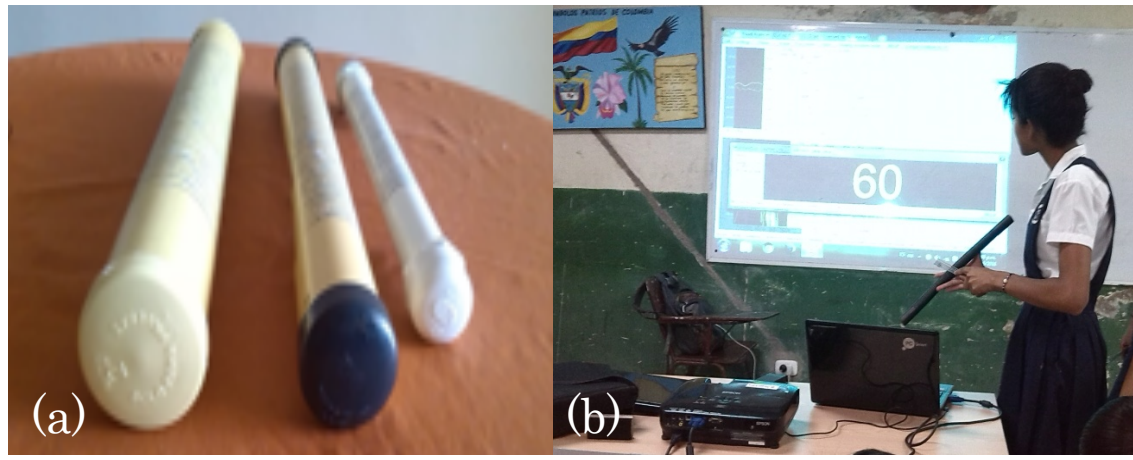

Source: (Mejia Reales, 2016)

Figure 8

Average Frequency: vs:

Diameter of the guacharaca.

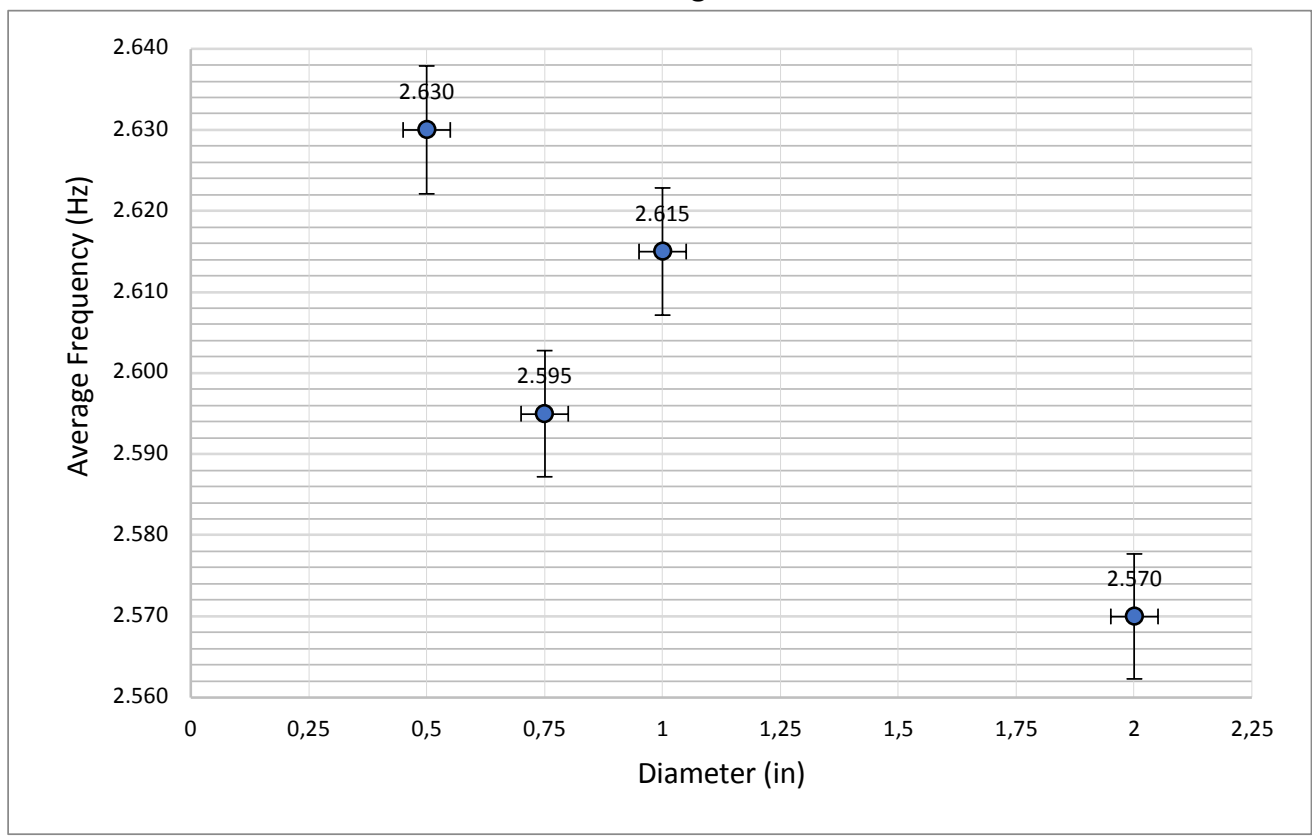

Source: (Mejia Reales, 2016) 
In the practice carried out with the students, it was found that, as the diameter of the guacharaca increases, the sound frequency emitted by it decreases slightly and the sound is perceived as a little deeper, but it was not possible to define a unique specific relationship between the variables although the experiment was repeated at least 20 times, it was possibly because the performer did not achieve a very constant rubbing frequency.

\subsection{Relationship between the frequency of the sound wave emitted by the guacharaca and the material with which it was constructed}

As a final point, the type of material with which the guacharaca was constructed changed, in this case: plastic (polyvinyl chloride PVC), cane arrow and Stainless Steel. To find the frequency emitted by the guacharaca as in previous experiences, the laptop, a high-frequency digital oscilloscope, and a video beam was implemented, for data analysis the tools were provided by Microsoft Excel ${ }^{\circledR}$ software.

\section{Figure 9}

(a) Guacharacas constructed with plastic (polyvinyl chloride PVC), cane arrow and Stainless Steel; (b) Screenshot of the visualization of the frequency of the sound emitted by the guacharacas.

(b)
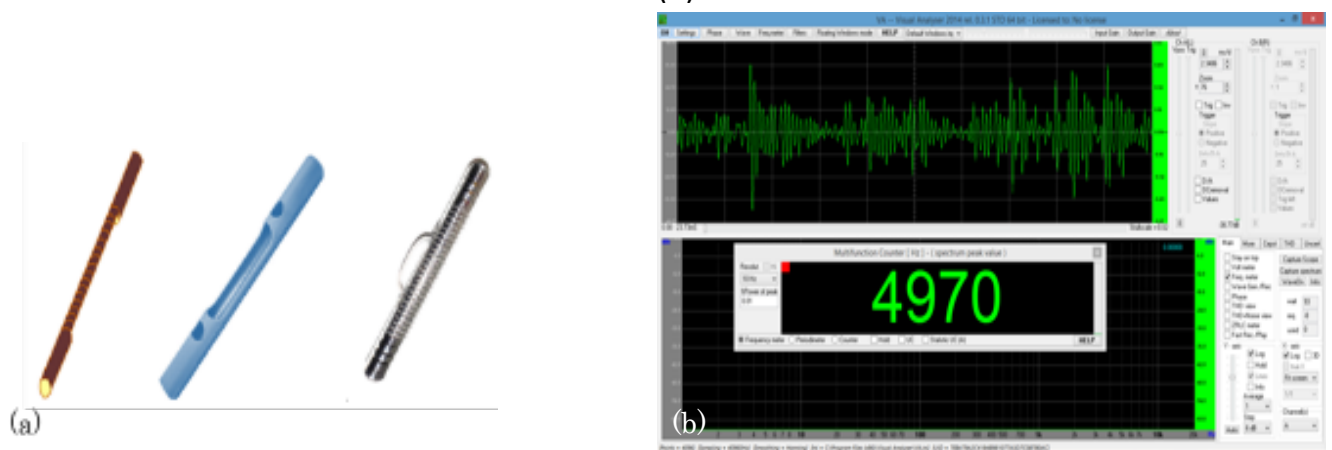

Source: (Mejia Reales, 2016)

After performing the practice with the students following the $A L M$ by performing twenty measurements for each case, it was found that for the PVC guacharaca the average frequency was $2,595 \pm 10 \mathrm{~Hz}$, for the Caña fleche (Gynerium sagittatum) the average frequency was $3,930 \pm 10 \mathrm{~Hz}$ and for the stainless steel the average frequency was $4,970 \pm 10 \mathrm{~Hz}$. From the previous results it is concluded that for the frequency of the sound emitted by the instrument depends on the material of which it was constructed and as it was expected, according to the predictions of the students, the one of minor sound frequency was the one of PVC and the one of major sound frequency the metallic one, being the most acute sound.

\section{Validation of the implemented didactic proposal}

In order to validate the teaching-learning process, both initial and final, tests were implemented in order to evaluate basic topics related with waves, (types of waves, concept of frequency, characteristics of sound, sound instruments), typical instruments of vallenato music and the relationship between the possible models and variables involved in the construction of a guacharaca and the frequency of the sound emitted by it.

With the purpose of comparing the results, the final test was composed of 12 questions, of which 8 inquire about the same subject matter as the initial test, but with a slight variation; Four more questions were included with the intention of going deeper in the concept of the frequency of the sound emitted by the guacharaca, exploring some possible knowledge about the relationship between the frequency of the sound and the different parameters of construction of the instrument, such as; the separation of the slots, the diameter of the guacharaca, the number of threads in the trenchs and the material with which the instrument is constructed. 
When observing the comparative results between the initial test and the final test shown in figure 10, it is evident that the performance at the general level improved notably.

Figure 10

Percentage of correct answers in terms of the question for input and output tests.

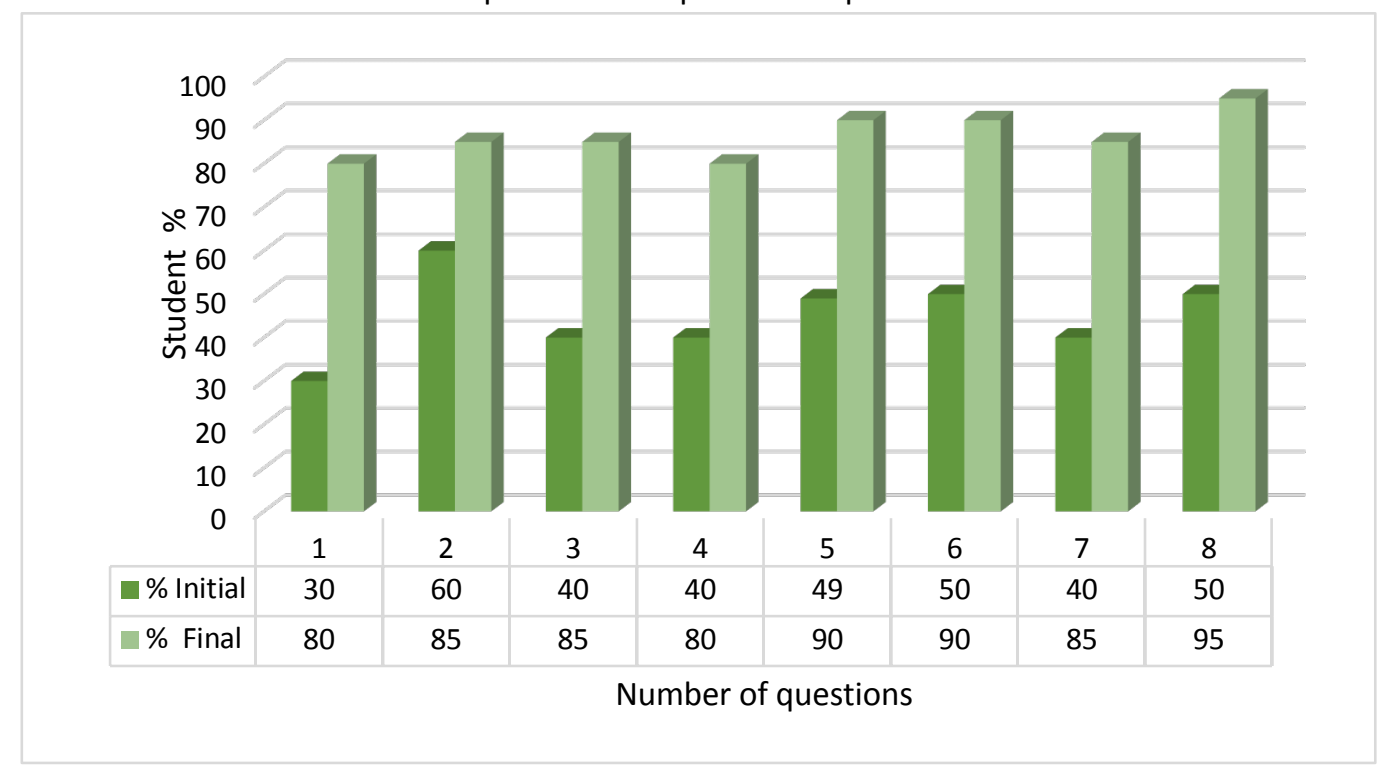

Source: (Mejia Reales, 2016)

Figure 10 shows the results of the experimental group in the two evaluations.

Figure 11

Comparison of correct and wrong answers

per students in the input and output tests.

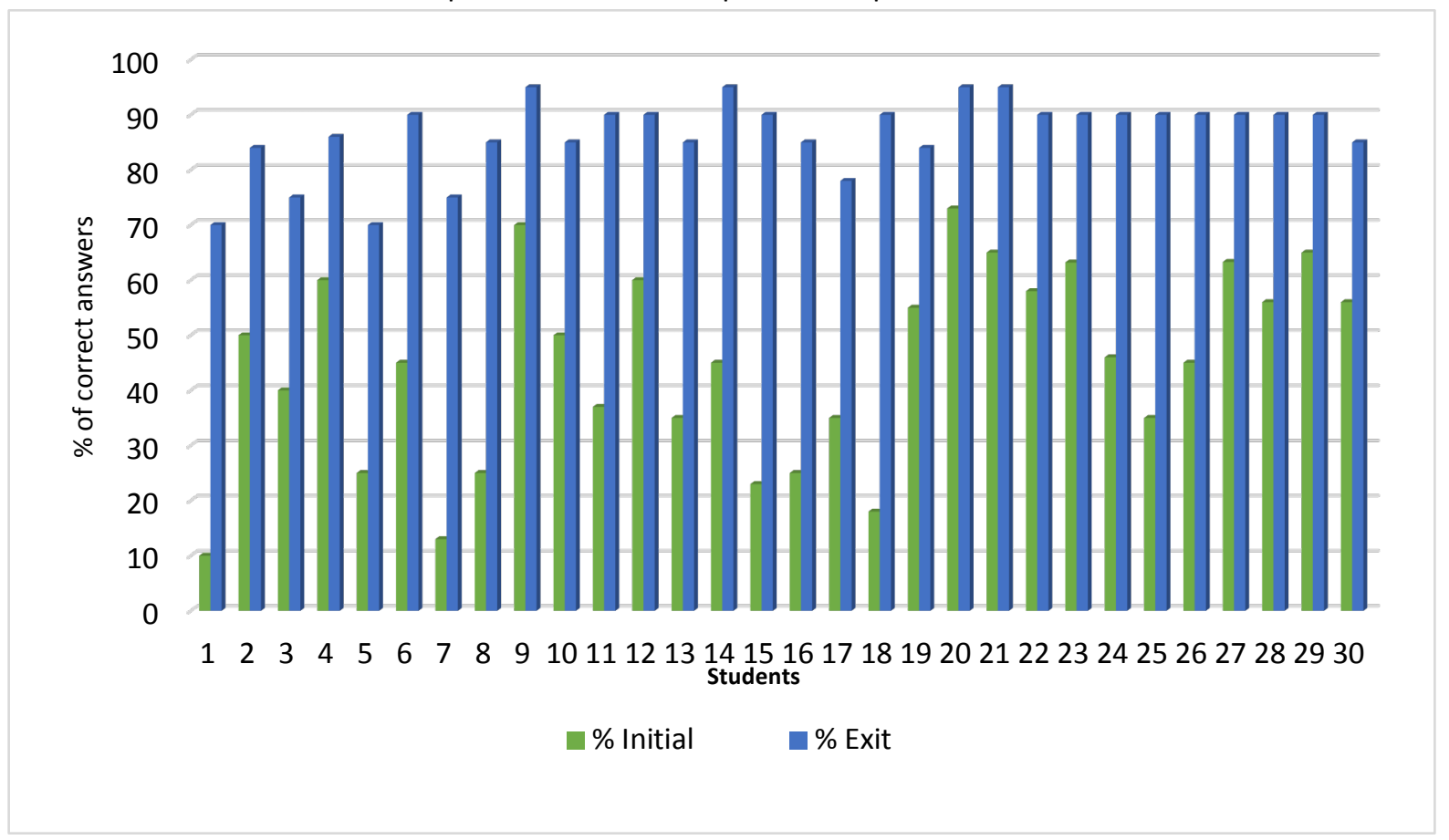

Source: (Mejia Reales, 2016) 
Figure 11 shows the comparative graph, by student, of the answers obtained in the entrance and exit tests. This clearly shows the significant progress made by all students, thus demonstrating that the ALM implemented was efficient and accurate.

To quantify this remarkable progress in the experimental activities carried out, the Hake's normalized gain factor (HNG) was (Hake, 1998). This HNG is normally applied to quantify the conceptual learning of the students for a determined method or strategy, comparing the results between the initial and the final test. It is used to determine the gain factor $g$ in the evaluation of groups in which a didactic component is present. This parameter accounts for the evolution of the student's learning and avoids the comparison between students who start a course better prepared than others. It also allows to determine if a teaching methodology is efficient with respect to the student's initial knowledge (Barbosa, et al., 2011).

The index $g$ is defined as the reason for the increase of the pre-test (entry test) and the post-test (final test) with respect to the maximum possible value. It is determined from the scores obtained on the assessment instrument used (Hake, 1998). If $\%<s_{i}>$ corresponds to the average percentage of correct answers in the input test and $\left.\%<s_{f}\right\rangle$ corresponds to the average obtained in the output test, the relative gain of conceptual learning for each student is determined with the following equation:

$$
g=\frac{\%<s_{f}>-\%<s_{i}>}{100-\%<s_{i}>}
$$

The normalized gain obtained in the above equation allows categorizing the data obtained in three zones as follows: low if $g \leq 0,3$, medium if $0,3<g \leq 0,7$ and high if $g>0,7$. With the results of the students in the applied tests it was observed that $66,6 \%$ were located in the high category, $33,3 \%$ in the medium category and $0 \%$ in the low category.

Also, by means of the equation:

$$
<\bar{g}>=\frac{1}{n} \sum_{i=1}^{n} g_{i}
$$

The average gain rate of all $n$ students was calculated, with $g_{i}$ the gain obtained by each student using equation (1). With the obtained data it was found that in this case $\langle\bar{g}\rangle=0,77$, placing the average of students in the high zone of the HNG. The above data numerically corroborate the efficiency of the teaching strategy used.

\section{Conclusions}

To teach high school students some basic concepts of sound waves, the strategy of using as a motivating element, the basic and rustic instrument representative of Colombian folk music from the Caribbean region, called "Guacharaca", was successfully applied. The software with the digital oscilloscope used to measure the sound frequency emitted by the instrument greatly simplified the work, due to its easy handling by the students. On the other hand, from the tests carried out with different performers of the musical instrument, it can be concluded that although there were variations in the sound frequency measured when changing the performer, the average sound frequency due to each performer differed by less than $10 \%$ of the average frequency of all the performers, which guarantees greater reproducibility of the results obtained; what turned out to be important is that the same performer will achieve an approximately constant friction frequency during their performance, this to make the result more reproducible.

The other hand by isolating the most relevant physical variables in the study of the sound frequency emitted by the guacharaca, the following were identified: the number of threads in the trench, the separation of the slots, 
the diameter of the instrument and the material of its construction. The only case in which a concrete mathematical relationship (increasing linear) could be established was between the number of threads of the trench and the measured sound frequency (a fact that is in accordance with the laws of classical mechanics as regards the force of kinetic friction refers, since as there are more threads in the carving, when rubbing them with the guacharaca, a greater number of molecules will vibrate, thus increasing the frequency of the sound waves), in the other cases although a decreasing sound frequency trend was observed as the spacing between grooves and the diameter of the instrument increased, a concrete mathematical relationship could not be identified. Finally, it is concluded that the frequency of the sound emitted by the guacharaca is higher in the guacharacas built with metal than in the others, as expected, since according to the metal, PVC has less rigidity and more elasticity than the metals used.

Regarding the didactic strategy used, it can be concluded that the ALM was the correct strategy, firstly because of its purely experimental nature (since the students of Valledupar enjoy doing physics experiments by playing the guacharaca) and also because the dynamics of the ALM it allows to learn autonomously and with a methodology far from the traditional one; this was evidenced by the high range in which the results of the tests applied when calculating the $H N G$ individually and in groups were located $(<\bar{g}>=0,77)$.

\section{Bibliographic references}

Barbosa, L. H., Mora, C. E., Talero, P. H. \& Organista, J. O., 2011. The Magic Blower: A Discrepant Experiment In The Learning Of The Bernoulli's Law Of Hydrodynamic Pressure. pp. 4309: 1-7.

Chaudhry, M. H., 2014. In: Basic Concepts in Applied Hydraulic Transients. New York: Springer-Verlag.

Doktorski, H., 1997. The Classical Free-Reed Inc.. [En línea]

Available at: http://www.ksanti.net/free-reed/description/taxonomy.html.

Gutiérrez Hinojosa, T. D., 1992. Cultura Vallenata: Origen, Teorías y Pruebas. En: Cultura Vallenata: Origen, Teorías y Pruebas. Santafe de Bogota: Plaza \& Janes Editores, p. 608.

Hake, R. R., 1998. Interactive-engagement versus traditional methods: A six-thousand-student survey of mechanics test data for introductory physics courses. American Journal of Physics, pp. 64-74.

Majdalawi, A. A., 2005. Acústica Musical. ETS Ing de Telecomunicaciones.

Marca Pais Colombia, 2015. COLOMBIA CO. [En línea]

Available at: https://www.colombia.co/cultura-colombiana/el-vallenato-es-reconocido-como-patrimonioinmaterial-de-la-humanidad/

Maynor, L., 2010. Instrumentos Musicales. [En línea]

Available at: https://sites.google.com/site/lauramaynorproyecto/4

Mejia Reales, J. M. \& Monroy-Ramirez, F. A., 2020. Estrategia Didáctica para el Estudio de la Frecuencia de las Ondas Sonoras Emitidas por un Instrumento Típico de la Música Vallenata: La Guacharaca.. Revista LASIRC (En línea), 1(6), pp. 111 - 113.

Mejia Reales, J. M., 2016. Estrategia Didactica Para el Estudio de la Frecuencia de las Ondas Sonoras Emitidas por un Instrumento Tipico de la Musica Vallenata: La Guacharaca, Bogota: Trabajo Final de Maestria, Universidad Nacional de Colombia.

Quiroz Otero, C., 1983. Vallenato, Hombre y Canto. En: Vallenato, Hombre y Canto. Bogota: Icaro Editores, p. 244. 
Sokoloff, D. R. \& Thornton, R. K., 1997. Using Interactive Lecture Demonstrations To Create an Active Learning Enviroment. The Physics Teacher, p. 340.

www.engineersedge.com, 2010. Ultimate - GD\&T Wall Chart. [En línea]

Available at: https://www.engineersedge.com/coeffients_of_friction.htm

www.vaxasoftware.com, 2007. Coeficientes de dilatacion termica lineal (a 20ㅡ). [En línea]

Available at: http://www.vaxasoftware.com/doc_edu/fis/coefidilat.pdf

\section{Esta obra está bajo una Licencia Creative Commons Attribución-NoCommercial 4.0 International \\ (cc) BY-NC}

